\title{
UNIVERSAL ZERO PATTERNS FOR SIMULTANEOUS SIMILARITY OF SEVERAL MATRICES
}

\author{
DRAGOMIR Ž. ĐOKOVIĆ
}

Abstract. Our field $F$ is algebraically closed. Let $M_{n}$ be the space of $n \times n$ matrices over $F$. If $\left(X_{1}, \ldots, X_{S}\right) \in M_{n}^{S}$ and $X_{k}=\left[x_{i j}^{(k)}\right]$, we say that the triple $(i, j, k)$ labels the entry $x_{i j}^{(k)}$. If $P$ is a collection of labels $(i, j, k)$, then $M_{P}$ denotes the subspace of $M_{n}^{S}$ consisting of $\left(X_{1}, \ldots, X_{S}\right) \in M_{n}^{S}$ such that $x_{i j}^{(k)}=0$ for all $(i, j, k) \in P$. We present a method of proving that certain patterns $P$, with $|P|=n(n-1) / 2$, are universal in the sense that for every $s$-tuple $\left(X_{1}, \ldots, X_{S}\right) \in M_{n}^{S}$ there exists $S \in \mathrm{GL}_{n}(F)$ such that $\left(S X_{1} S^{-1}, \ldots, S X_{S} S^{-1}\right) \in M_{P}$. We demonstrate the power of our method on several examples from recent literature.

Mathematics subject classification (2000): 15A21, 14L35.

Key words and phrases: Simultaneous similarity of matrices, unitary similarity, zero patterns.

\section{REFERENCES}

[1] K. BongarTz, Some geometric aspects of representation theory, Algebras and Modules I, (I. Reiten, S.O. Smalø, Ø. Solberg, editors), CMS Conf. Proc. 23 (1998), 1-27.

[2] K. R. DAVIDSON AND D. Ž. ĐoKOvić, Tridiagonal forms in low dimensions, Linear Alg. Appl. 407 (2005), 169-188.

[3] D. Ž. ĐoKOVIĆ AND C. R. JoHNSON, Unitarily achievable zero patterns and traces of words in A and $A^{*}$, Linear Alg. Appl. 421 (2007), 63-68.

[4] S. FrIEDlAnd, Simultaneous similarity of matrices, Advances in Math. 50 (1983), 189-265.

[5] M. GECK, An Introduction to Algebraic Geometry and Algebraic Groups, Oxford University Press, 2003.

[6] J. HARRIS, Algebraic Geometry, A First Course, Springer-Verlag, New York, 1992.

[7] J. HolbROOK AND J.-P. SCHOCH, Moving zeros among matrices, with an appendix by T. Košir and B.Al. Sethuraman, Linear Alg. Appl. (to appear).

[8] V. PATI, Unitary tridiagonalization in $M(4, \mathbf{C})$, Proc. Indian Acad. Sci. (Math. Sci.) 111 (2001), 381-397.

[9] H. RadjaVi And P. Rosenthal, Simultaneous Triangularization, Springer-Verlag, New York, 2000.

[10] H. SHAPIRO, A survey of canonical forms and invariants for unitary similarity, Linear Alg. Appl. 147 (1991), 101-167.

[11] R. SteInBERG, Conjugacy Classes in Algebraic Groups, Notes by Vinay V. Deodhar, Lect. Notes in Math. vol. 366, Springer-Verlag, Berlin-New York, 1974. 